\title{
Mechanical Properties, Tribology and Electrochemical Studies of Al/Fly Ash/Eggshell Aluminium Matrix Composite
}

\author{
Ndudim H. Ononiwu ${ }^{1,2, *}$, Chigbogu G. Ozoegwu ${ }^{1,2}$, Nkosinathi Madushele ${ }^{1}$, Ojo Jeremiah Akinribide ${ }^{3}$, \\ Esther T. Akinlabi ${ }^{4,1}$ \\ Department of Mechanical Engineering Science, University of Johannesburg, South Africa
Department of Mechanical Engineering, University of Nigeria Nsukka Nigeria
Centre for Nanoengineering and Tribocorossion, University of Johannesburg, Johannesburg, South Africa
Pan African University for Life and Earth Sciences Institute (PAULESI), Ibadan, Nigeria
Correspondence: $219122653 @$ student.uj.ac.za, ndudim.ononiwu@ @unn.edu.ng (N.H.O.);
}

\begin{abstract}
This work was carried out to investigate the effect of carbonized eggshells (CES) and fly ash on the microstructure, mechanical properties, wear, and corrosion characteristics of Al-Si12. The weight fraction (wt.\%) of the CES particles was kept constant at $2.5 \mathrm{wt} . \%$, while that of fly ash was varied at $2.5 \mathrm{wt} . \%, 5.0 \mathrm{wt} . \%, 7.5 \mathrm{wt} . \%$, and $10.0 \mathrm{wt} . \%$. The selected fabrication route was stir casting. The x-ray diffraction (XRD) analysis of the cast aluminum matrix composites (AMCs) revealed the presence of phases including $\alpha$-aluminum, $\mathrm{SiO}_{2}$, and $\mathrm{Si}$ with the formation of the intermetallic $\mathrm{CuAl}_{2}$ phase. The microhardness of the cast samples increased with increasing weight fraction of the reinforcements up to the $7.5 \mathrm{wt} . \%$ fly ash sample. The tensile strength and compressive strength were highest for the 2.5 wt. $\% / C E S ~ 2.5$ wt. $\%$. Tribology studies showed that the lowest wear rate of $4.91 \times 10^{-5} \mathrm{~mm}^{3} / \mathrm{Nmm}$ was obtained for the $2.5 \mathrm{wt} . \%$ fly ash sample, while the corrosion studies showed that the corrosion rate of $2.70 \times 10^{-5} \mathrm{~g} / \mathrm{hr}$ was lowest for the $2.5 \mathrm{wt} . \%$ fly ash as well.
\end{abstract}

Keywords: AMC; microstructure; mechanical properties; stir casting; tribology; corrosion.

(C) 2021 by the authors. This article is an open-access article distributed under the terms and conditions of the Creative Commons Attribution (CC BY) license (https://creativecommons.org/licenses/by/4.0/).

\section{Introduction}

The need for continuous improvements in the production and manufacturing of engineering components has received numerous attention. This ever-present need has led to the improvement of production processes, methods, and material selection processes. In the area of material selection, the major aim of the research currently being carried out is the fabrication of lightweight materials with improved corrosion and wear resistance while maintaining the required strength for adequate application in the required areas of interest. These desirable property improvements are achieved in composite materials. Composite materials, simply put, are materials engineered through the combination of 2 or more materials with dissimilar physical and chemical properties to enhance the properties of the selected base material. Composite materials are classified based on the matrix materials into metal matrix composites (MMCs), polymer matrix composites (PMCs), and ceramic matrix composites (CMCs) [1]. MMCs have received strong attention and have been applied to aerospace [2], automobile [3], marine, and sports [4]. Aluminum has received the most interest among the available metals already applied as base metals in MMCs, such as titanium, magnesium, copper, and iron [5]. 
This is not only due to its availability but for its strength, lightweight, and good corrosion resistance. Aluminum is generally reinforced with specific particles to either improve or replace an existing application. The fabrication of aluminum matrix composites (AMCs) has led to the development of materials with improved weight, specific strength, stiffness, wear resistance, and corrosion resistance [6]. The fabrication of these MMCs is achieved through several production processes such as stir casting, powder metallurgy, and infiltration method. However, several researchers have generally preferred the stir casting route due to its relatively low cost, simplicity, and ability to produce complex geometries $[7,8]$.

The recorded improvements in the properties of MMCs have resulted from the incorporation of a second phase into the fabrication process, generally referred to as reinforcements. Several researchers have used synthetic materials for this purpose. Such reinforcements include $\mathrm{SiC}, \mathrm{Al}_{2} \mathrm{O}_{3}$, and $\mathrm{B}_{4} \mathrm{C}$. There have been numerous researches with recorded merits in improving the mechanical, corrosion, and wear properties. Although this has been the case, there has been the issue of cost reduction in the fabrication process of MMCs. Although the introduction of stir casting has reduced an aspect of the cost, the high cost of synthetic reinforcements has led to research into more cost-effective alternatives. The search for alternatives has cultivated an interest in using materials perceived to be waste as reinforcements. These materials are categorized into agricultural and industrial wastes. Research into these waste materials, also regarded as sustainable materials, has identified constituents including $\mathrm{SiO}_{2}, \mathrm{Al}_{2} \mathrm{O}_{3}, \mathrm{Fe}_{2} \mathrm{O}_{3}, \mathrm{CaCO}_{3}$ [9-11], which are excellent candidates for reinforcement particulates.

Research in AMCs has shifted from the production of binary materials to ternary materials. This has been the case to compensate for the cost, improve properties, and improve the machinability of these materials [12-15]. Ternary AMCs utilize hybrid reinforcements, i.e., the combination of 2 or more particulates to reinforce the base metal. The combination of synthetic and sustainable materials has been the most utilized hybrid reinforcement for AMC production. It is seen from reviewed works that more than $70 \%$ of research into the production of ternary AMCs has incorporated fly ash as the second reinforcing phase. This is due to its low density, availability, and cost [16]. Research, reported in [17-20], who have reinforced aluminum with hybrid reinforcements have recorded improvements in density, tensile strength, hardness, and tribocorrosive properties. Successful research involving the addition of fly ash as a $2^{\text {nd }}$ reinforcing phase includes work reported [21] where A356 was reinforced with varying weight fractions of fly ash and $\mathrm{SiC}$. Results of the investigation revealed improvements in tensile strength, hardness, and fatigue strength. In [22], the authors evaluated the sliding wear behavior of AA7075/B 4 C/fly ash hybrid AMC. The investigation reported a lower wear rate and coefficient of friction of the hybrid AMC in comparison to the base metal. In [23], the authors reinforced aluminum with $10 \mathrm{wt} . \% \mathrm{SiC}$ and varying weight fraction of Fly ash $(5 \%$, $10 \%$ and $15 \%$ ). It was reported that there was a reduction in density with increasing weight fraction of Fly ash in the hybrid AMC. This was also the case for the evaluation of the hardness. It was also reported that the wear resistance of the hybrid AMC improved in comparison to the base metal.

Eggshells are waste products obtained from agricultural and food production industries. They are predominately composed of $\mathrm{CaCO}_{3}$ and a trace amount of organic matter [20]. Carbonized eggshells have been considered as reinforcements for environmental sustainability and cost reduction. In addition, they have been successfully applied as reinforcements where there have been recorded improvements in mechanical and physical properties [25,26]. 
Eggshells have also been effectively applied in the fabrication of ternary AMC as reported in [27], where AA 2014 was reinforced with eggshell and $\mathrm{SiC}$ in varying weight fractions. The investigation revealed an improvement in the specific strength, cost, density, and thermal expansion compared to the base metal and the single reinforced AMC. In [28], the corrosion resistance properties of AA6063/CES/rice husk ash were evaluated. The results showed that the prevalent corrosion mechanism of the AMC was localized pitting formed due to the deposition of the corrosion products.

Furthermore, an improvement in the corrosion rate was recorded with the increasing weight fraction of the hybrid reinforcements. Research by Durowoju et al. [29] showed that the addition of carbonized eggshells to aluminum reinforced with graphite and $\mathrm{SiC}$ decreased the density of the base metal. Analysis of the microhardness of the fabricated samples also showed that the ternary AMC improved by $19.9 \%$ compared to the $\mathrm{Al} / \mathrm{Gr}$ composite and $18.13 \%$ compared to the $\mathrm{Al} / \mathrm{SiC}$ binary composite. They indicated that the addition of the carbonized eggshell phase is capable of improving the physical and mechanical properties of binary reinforced AMCs.

From the literature survey, the utilization of both synthetic and sustainable reinforcements for the fabrication of ternary AMCs has been explored. The reviewed works have identified improvements to the characterized aluminum matrix. However, the effects of combining 2 sustainable materials as reinforcements in AMCs have received very little attention. This research attempts to fill this obvious research gap by exploring the possibility of fabricating a hybrid AMC by combining fly ash and carbonized eggshells to investigate their effect on the mechanical properties, wear resistance, and corrosion resistance properties of AlSi12.

\section{Materials and Methods}

\subsection{Reinforcement preparation.}

For this study, fly ash and carbonized eggshells were selected as the reinforcing phases for the fabrication of the composites. The fly ash was sourced from Ash Resources in South Africa. Eggshells were sourced from eateries and bakeries around Auckland Park Johannesburg. These eggshells were subsequently washed and sundried to remove all traces of organic matter. The now sundried eggshells were further dried in an electric oven at $80^{\circ} \mathrm{C}$ for 48 hours to remove any residual moisture. Ball milling of the eggshell commenced at a speed of $180 \mathrm{rpm}$ for 7 hours to reduce the particles to microscale.

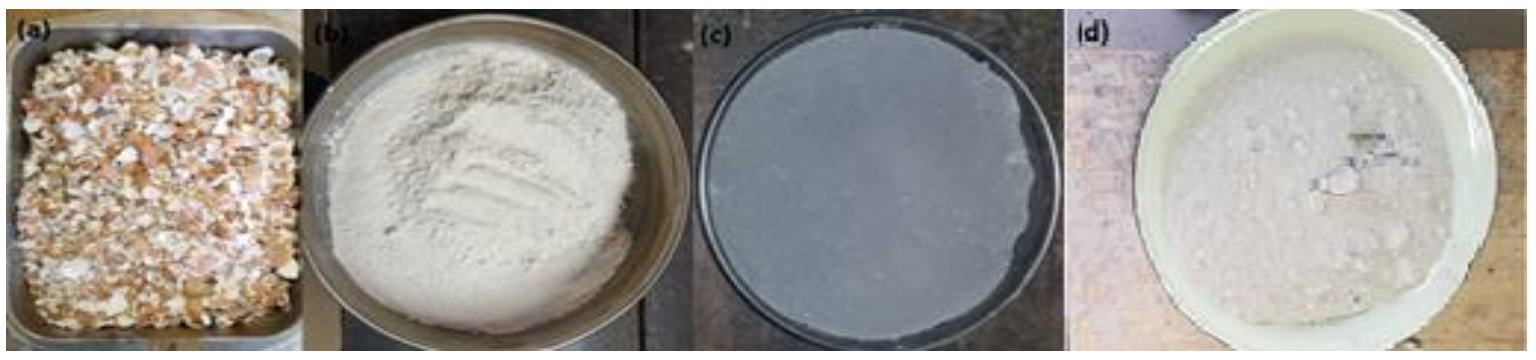

Figure 1. Particulate reinforcements (a) Sourced eggshells; (b) Milled eggshells; (c) Carbonized eggshells at $800^{\circ} \mathrm{C}$; (d) Fly ash.

The milled eggshells were carbonized at a temperature of $800^{\circ} \mathrm{C}$ for 2 hours to remove volatile matter, increase the carbon content of the eggshell particles, reduce moisture content 
and improve interfacial bonding between the eggshell particles and the matrix phase [30]. The fly ash and carbonized eggshell samples were screened using the Filtra vibration S.L Model FTL-0200 sieve shaker for 30 minutes. The selected fly ash and carbonized eggshells for the fabrication of the composites had a particle size range of $\leq 75 \mu \mathrm{m}$. The particulate reinforcements selected for this study are shown in Figure 1.

\subsection{Composite fabrication.}

The aluminum alloy selected for this study was Al-Si12. Al-Si12 is an aluminum cast alloy with excellent corrosion resistance, excellent ductility, and medium strength. Its high silicon content decreases its machinability. Al-Si12 was selected as the base metal for this study due to its excellent casting properties, including high fluidity and low susception to hot-tearing. The elemental composition of the aluminum alloy used for this study is shown in table 1 .

Table 1. Elemental composition of the aluminum matrix.

\begin{tabular}{l|l|l|l|l|l|l|l|l|l} 
Element & $\mathrm{Al}$ & $\mathrm{Si}$ & $\mathrm{Fe}$ & $\mathrm{Cu}$ & $\mathrm{Mn}$ & $\mathrm{Zn}$ & $\mathrm{Co}$ & $\mathrm{Sn}$ & $\mathrm{Ti}$ \\
\hline \% Composition & 84.01 & 6.23 & 0.35 & 3.33 & 0.14 & 5.85 & 0.01 & 0.05 & 0.03
\end{tabular}

The AMC was fabricated via the stir casting liquid metallurgy route. To produce the composites, the matrix to reinforcement proportions specified in table 2 were used. Keeping the weight fraction of CES constant, the Fly ash was varied from $2.5 \mathrm{wt} . \%$ to $10 \mathrm{wt} \%$ in increments of $2.5 \mathrm{wt} . \%$. The objective of this weight fraction distribution was to ensure that the maximum reinforcement composition was not greater than $12.5 \%$. This was necessary because from previous experiments, the increase in the weight fraction above $12.5 \mathrm{wt} . \%$ results in an increase in the viscosity of the melt to a point where the uniform dispersal of the reinforcements becomes difficult to achieve.

Table 2. Designation and proportions of the matrix and hybrid reinforcements.

\begin{tabular}{l|l|l|l|l} 
Designation & $\begin{array}{l}\text { Aluminium } \\
(\mathbf{w t . \%})\end{array}$ & $\begin{array}{l}\text { Carbonized Eggshell } \\
(\mathbf{C E S})(\mathbf{w t . \%})\end{array}$ & $\begin{array}{l}\text { Fly ash } \\
(\mathbf{w t . \%})\end{array}$ & $\begin{array}{l}\text { CES + Fly ash } \\
(\mathbf{w t . \%})\end{array}$ \\
\hline L0 & 100 & 0.0 & 0.0 & 0.0 \\
\hline L1 & 95 & 2.5 & 2.5 & 5.0 \\
\hline L2 & 92.5 & 2.5 & 5.0 & 7.5 \\
\hline L3 & 90 & 2.5 & 7.5 & 10.0 \\
\hline L4 & 87.5 & 2.5 & 10.0 & 12.5
\end{tabular}

The Al-Si12 base metal sourced from the Foundry laboratory in the University of Johannesburg DFC campus was used. The Al alloy which was received as blocks were subsequently cut and weighed based on the designed weight fractions. The base metal was then charged into a preheated graphite crucible, and the temperature of the electric furnace was set to $760^{\circ} \mathrm{C}$. The permanent die and steel stirrer were also preheated but to a temperature of $350^{\circ} \mathrm{C}$ $\pm 20^{\circ} \mathrm{C}$. This was done to ensure uniform flow and solidification of the melt during cooling and avoid the temperature differential between the stirrer and the aluminum melt. The weighed hybrid reinforcements (fly ash and CES) were charged in a preheated ceramic crucible, and the temperature of the muffle furnace was increased to $400^{\circ} \mathrm{C}$ and preheated for 1 hour. $1 \mathrm{wt} . \%$ magnesium was introduced after the reinforcement was charged into the melt to improve wettability and interfacial bonding between the reinforcing particles and the matrix. Mechanical stirring was done in 2 steps to ensure adequate dispersal of the reinforcement particles in the aluminum matrix. The 1 st stirring was done immediately after introducing the 
reinforcements and the magnesium, while the 2nd stage was done just before casting the molten AMC.

\subsection{Experimental procedure.}

The D8, Discover, make (Bruker US) with CuKa radiation of $1.54181 \hat{\mathrm{A}}$ wavelength generated at $40 \mathrm{~mA}$ and $40 \mathrm{KV}$ was used to conduct fly ash's X-ray diffraction (XRD) analysis, CES, and cast composite samples. A continuous scan mode and scan range of $5^{\circ}$ to $90^{\circ}$ degrees were chosen for the XRD analysis of all the samples under investigation. The XRD for the composites was conducted to identify the phases present and investigate the presence of intermetallic compounds. The metallographic analysis was used to determine and analyze the level of dispersion of the reinforcements in the aluminum matrix and identify the presence of anomalies. To study the corrosion and wear mechanisms, metallography studies were also conducted. All these were done using the TESCAN model type VEGA 3 LMH scanning electron microscope.

For this study, the mechanical properties under investigation were microhardness, tensile strength, and compressive test. The microhardness was obtained using the Times Vickers microhardness tester. A diamond indenter was used to make the necessary indentations. These indentations for repeatability were taken at 5 points $1 \mathrm{~mm}$ apart. The average microhardness was obtained based on the indentations made. The test force selected for this study was $3 \mathrm{~N}$ with a dwell time of 15 seconds per indentation. The average microhardness was obtained for each of the samples. The tensile strength test was carried out on the MKS Universal tensile testing machine with a frame capacity of $1000 \mathrm{KN}$ per the ASTM E8 standard, while the compressive strength was carried out on the Zwick/Roell Universal tensile testing machine. 3 cylindrical specimens of $20 \mathrm{~mm}$ X $30 \mathrm{~mm}$ were employed for this study. All tests related to the determination of the mechanical properties of the samples under consideration were done at $20^{\circ} \mathrm{C}$. The examination of the density and porosity of the base metal and cast AMC were also objectives of this investigation. The experimental density was obtained using the Archimedes principle shown in equation 1 , while the theoretical density was obtained via the rule of mixture shown in equation 2.

$$
\rho_{\mathrm{e}}=\frac{\mathrm{m}}{\mathrm{v}}
$$

where $\rho_{\mathrm{e}}$ is the experimental density, $\mathrm{m}$ is the mass of the sample, and $\mathrm{v}$ is the displaced volume.

$$
\rho_{t}=\rho_{m}\left(w t \%_{m}\right)+\rho_{f}\left(w t \%_{f}\right)+\rho_{c}\left(w t \%_{c}\right)
$$

where $\rho_{\mathrm{t}}$ is the theoretical density of the composite sample, $\rho_{\mathrm{m}}$ is the density of the matrix, $\mathrm{wt} \% \mathrm{~m}$ is the weight fraction of the matrix, $\rho_{\mathrm{f}}$ is the density of the fly ash, wt $\%_{\mathrm{f}}$ is the weight fraction of the fly ash, $\rho_{c}$ is the density of the carbonized eggshell and $w t \%_{c}$ is the weight fraction of the carbonized eggshells.

The porosity study was used to analyze the formation of pores in the cast AMC. This is an important aspect of the studies as the behavior of the pores affects the properties of the fabricated composite. The porosity of the cast AMCs was calculated using equation 3.

$$
\mathrm{P}=\left(1-\frac{\rho_{\mathrm{e}}}{\rho_{\mathrm{t}}}\right) \times 100 \%
$$

where $\mathrm{P}$ is the percentage porosity and $\rho_{\mathrm{e}}$ is the experimental density of the cast AMC.

The Rtec MTF 5000 Universal ball-on-disc tribometer was used to determine the coefficient of friction and the wear volume. The ball selected for this study was an E521000 
steel alloy grade 25 of $6 \mathrm{~mm}$ diameter. The wear rate was obtained using the Archard equation shown in equation 4 ,

$$
\mathrm{K}=\frac{\mathrm{V}}{\mathrm{ws}}
$$

where $\mathrm{K}$ is the wear rate, $\mathrm{V}$ is the worn volume, $\mathrm{w}$ is the normal load, and $\mathrm{s}$ is the sliding distance. For the tribology studies, Keeping the load constant at $30 \mathrm{~N}$, the coefficient of friction (COF) and wear rate were obtained to ascertain the influence of the reinforcement on the aluminum matrix for wear-resistant applications. Table 3 shows the parameters selected for this study.

Table 3. Tribology analysis parameters.

\begin{tabular}{l|l} 
Parameters & Values \\
\hline Sliding distance & $120 \mathrm{~mm}$ \\
\hline Sliding time & $120 \mathrm{secs}$ \\
\hline Sliding velocity & $1 \mathrm{~mm} / \mathrm{s}$
\end{tabular}

The corrosion behavior of the cast samples was investigated with the aid of the $\mathrm{HCH}$ Instruments electrochemical analyzer equipped with a Silver/Silver chloride reference electrode stored in $\mathrm{KCl}$ and platinum counter electrode. The samples for this study were used as the working electrode. To study the corrosion behavior, each sample with an insulated copper wire attached with aluminum conductive tape was cold mounted in resin and left to cure for 20 mins. The samples were prepared by grinding the surface to be exposed progressively with waterproof $\mathrm{SiC}$ paper up to 4000 grits. The exposed surfaces were subsequently washed in distilled water and degreased with acetone to remove any trace of contaminants that could impede the accuracy of the obtained results. The medium for this electrochemical study was $3.5 \% \mathrm{NaCl}$. All the experiments were conducted at room temperature. The potentiodynamic polarization analysis was conducted at a polarization range of $-1.5 \mathrm{~V}$ to $1.5 \mathrm{~V}$ and a scan rate of $0.0002 \mathrm{~V} / \mathrm{s}$. The corrosion medium was replaced after each experiment to ensure the validity of the results obtained. The corroded samples after each run were stored carefully for microstructural examination to investigate the corrosion mechanisms.

\section{Results and Discussion}

\subsection{Microstructural characterization.}

The microstructural characterization of the individual reinforcing phases and the cast composites was conducted.
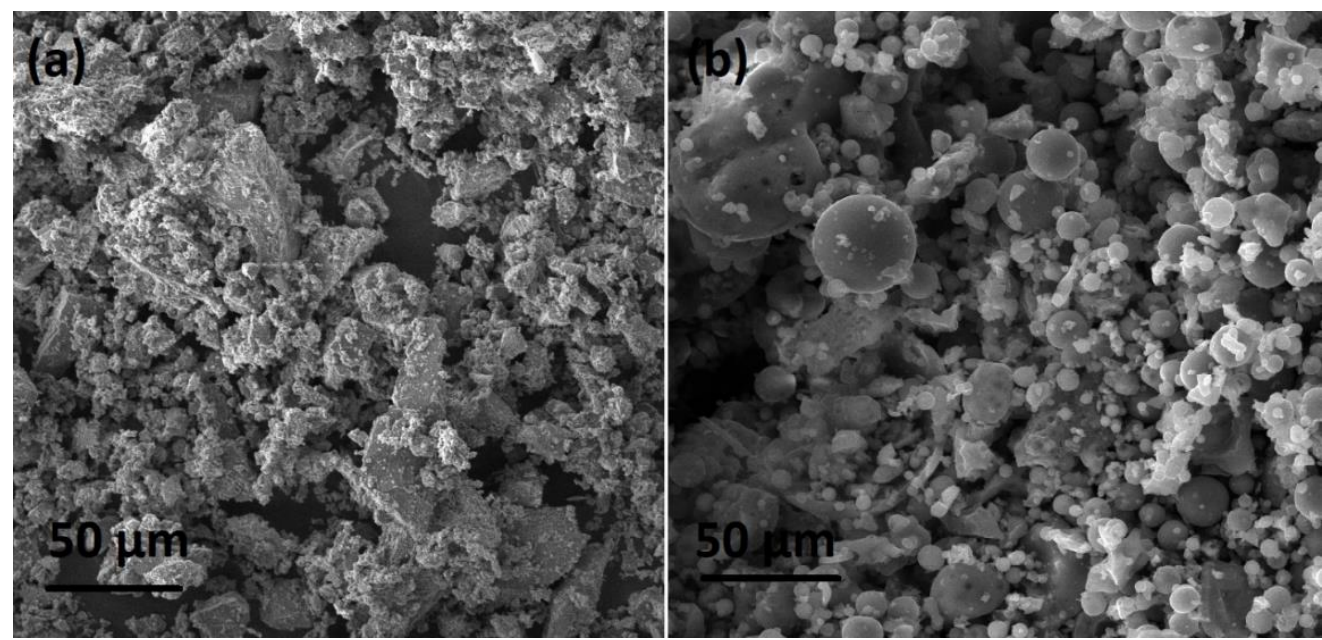

Figure 2. SEM micrographs for (a) carbonized eggshell; (b) fly ash. 
The microstructural characterization of fly ash particles revealed the presence of mostly spherically shaped particles, usually in the form of hollow spheres. The extended ball milling time of the samples altered the morphology of the fly ash particles by plastically deforming some of the particles. As evident in Figure 2 (a), this plastic deformation resulted in irregularly shaped particles [31]. The average particle size of the fly ash particles is $19.18 \mu \mathrm{m}^{2}$. As evident in Figure 2 (b), the morphology of the CES particles showed predominantly irregularly shaped particles. The average particle size of the CES samples was $27.48 \mu \mathrm{m}^{2}$.

The examination of the morphology of the cast samples shows the formation of an interdendritic $\alpha$-aluminum phase. This was formed during the solidification of the casts. In the case of the composites, sample L1 revealed uniform dispersion of both reinforcements in the aluminum matrix pool, which signifies proper stirring action during the fabrication of the composites. Further analysis of the micrographs of sample L1 shows no visible presence of pores which signifies proper casting and uniform cooling of the sample. Sample L2 reported a fairly uniform dispersion of the hybrid reinforcements in the matrix pool, although both reinforcements had a slight agglomeration. Sample L3 and L4, as seen in the micrographs shown in Figure 3, revealed the presence of agglomerations and clustering of the reinforcing particles. Although the dispersion of the reinforcements for sample L3 was fairly uniform, the eggshells showed some agglomeration and segregation. The fly ash particles, on the other hand, showed minimal segregation.
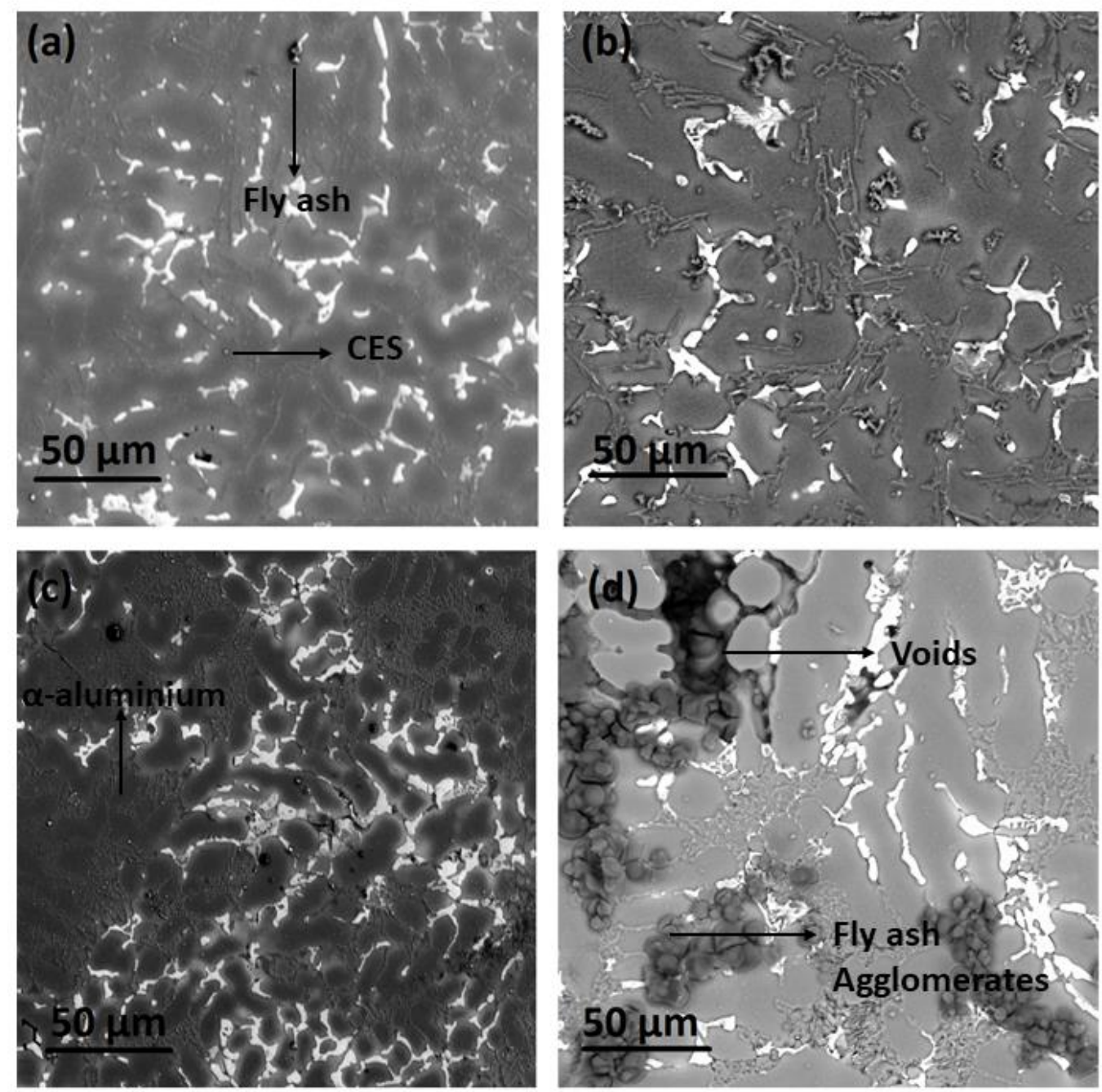

Figure 3. SEM micrographs for samples (a) L1; (b) L2; (c) L3; (d) L4. 
The formed cluster could also be a result of the difference in thermal properties between the reinforcing phase and the aluminum matrix during the fabrication process. Sample L4 showed an extreme presence of pores and agglomeration of the fly ash particles. This could be due to the increased viscosity of the melt and the difference in densities of both reinforcement particles. Another reason for the extensive segregation and agglomeration in sample L4 is due to the difference in melting temperature between the reinforcing particles and the matrix and the delay in the solidification rate due to the increased weight fraction of the reinforcements [32]. The SEM micrographs for sample L4 also showed the presence of pockets of air in the form of pores as a result of the clustering of the reinforcing particles [33]. The morphological characterization of the cast samples showed the formation of agglomerations, segregations, and porosity as a function of increasing the weight fraction of both reinforcements.

The XRD analysis of the fly ash samples identified mullite $\left(3 \mathrm{Al}_{2} \mathrm{O}_{3} \mathrm{SiO}_{2}\right)$, quartz $\left(\mathrm{SiO}_{2}\right)$, alumina $\left(\mathrm{Al}_{2} \mathrm{O}_{3}\right)$, wustite $(\mathrm{FeO})$, and hematite $\left(\mathrm{Fe}_{2} \mathrm{O}_{3}\right)$ as major crystalline phases. The qualitative analysis of the fly ash particles, as shown in Table 4, shows mullite and quartz as the predominant phases. Analysis of the CES particles revealed that eggshell contains predominantly $\mathrm{CaCO}_{3}$. The quantitative analysis shows the presence of $\mathrm{CaCO}_{3}$ in the form of aragonite. Quantitative analysis of the fly ash and CES as revealed via the XRD is summarized in Table 4. The XRD spectrum of the fly ash and CES reinforcements is depicted in Figure 4.

Table 4. Quantitative analysis of the carbonized eggshells and fly ash obtained via XRD analysis.

\begin{tabular}{c|c|c|c}
\multicolumn{2}{c|}{ Carbonized eggshell (CES) } & \multicolumn{2}{c}{ Fly ash } \\
\hline Constituent & $\%$ & Constituent & $\%$ \\
\hline Calcium & 8.67 & Mullite $\left(3 \mathrm{Al}_{2} \mathrm{O}_{3} \mathrm{SiO}_{2}\right)$ & 50.63 \\
\hline Aragonite & 91.33 & Quartz $\left(\mathrm{SiO}_{2}\right)$ & 41.05 \\
\hline & & Hematite $\left(\mathrm{Fe}_{2} \mathrm{O}_{3}\right)$ & 4.23 \\
\hline & & Wustite $(\mathrm{FeO})$ & 0.65 \\
\hline & & Alumina $\left(\mathrm{Al}_{2} \mathrm{O}_{3}\right)$ & 3.25
\end{tabular}

(a)

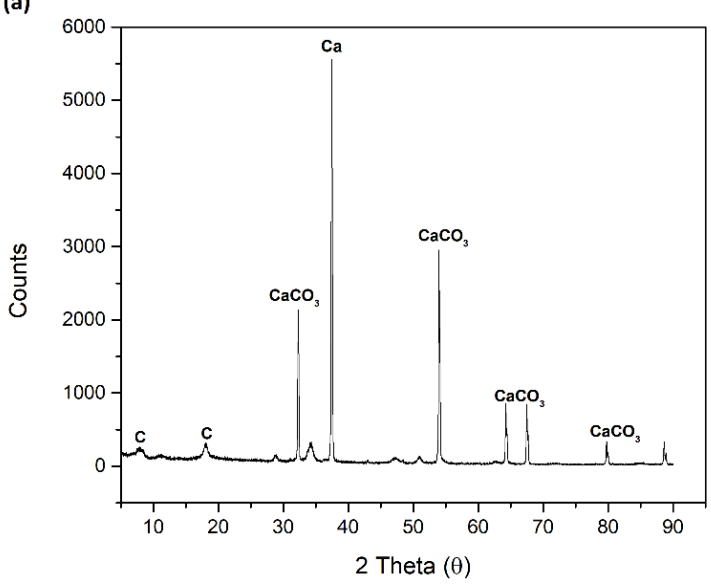

(b)

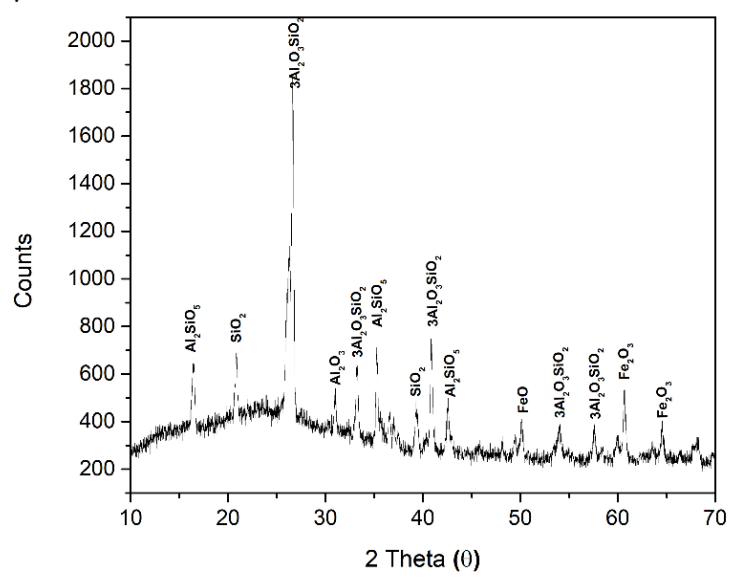

Figure 4. XRD patterns of the (a) carbonized eggshells and (b) fly ash.

The X-ray diffractometry analysis was conducted to ascertain the present phases in the cast composites. The XRD spectrum of the cast composites is shown in Figure 5. The XRD results of sample $\mathrm{L} 1$ show the different phases at various peaks. $\mathrm{SiO}_{2}$ and aluminum are the dominant peaks in the aforementioned sample. There is an increase in the number of phases present in the hybrid AMCs, which can be attributed to the addition of hybrid reinforcements. The $\mathrm{SiO}_{2}$ phases present and their different peak intensities are significant in the XRD plot. The XRD analysis recorded the formation of the $\mathrm{CuAl}_{2}$ intermetallic phase. The copper 
aluminide $\left(\mathrm{CuAl}_{2}\right)$ phase is an intermetallic compound formed during the gradual cooling of the single solid $\alpha$-phase to room temperature. The presence of the intermetallic $\mathrm{CuAl}_{2}$ phase is responsible for the increased brittleness of the cast composites. The plots also showed that the peak intensity of the $\mathrm{CuAl}_{2}$ phase decreased with the increasing weight fraction of the reinforcements.

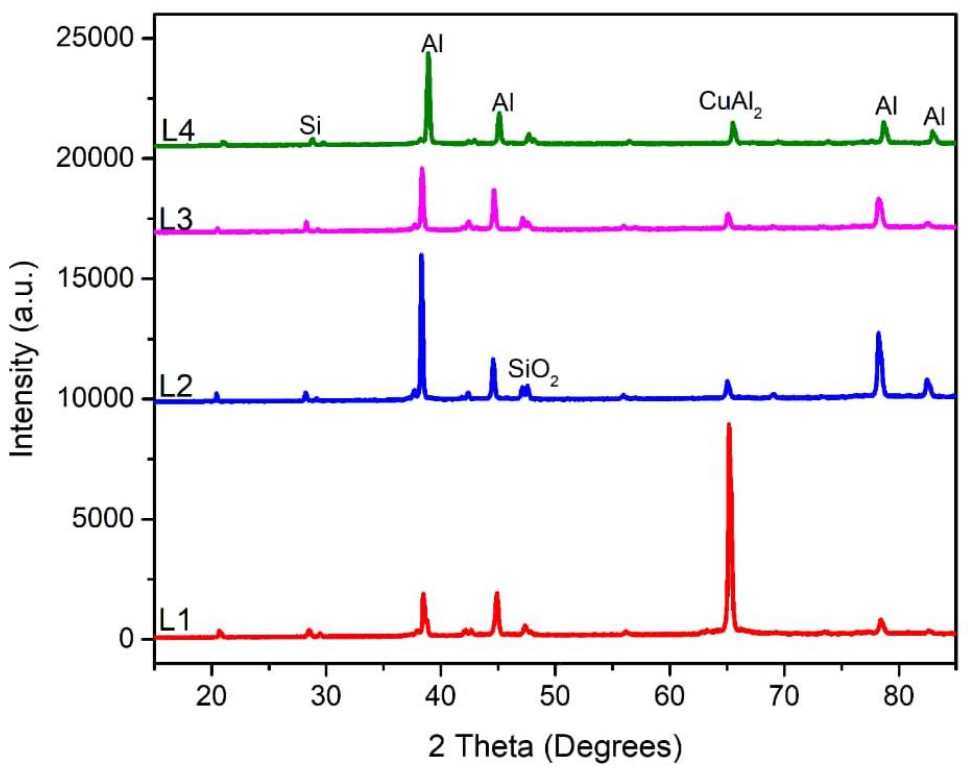

Figure 5. XRD Patterns of the cast AMCs.

The four crystal planes of $\mathrm{Al}$ (111), (200), (220), and (311) with the dominant (111) orientation are found in the AMC samples under consideration. The peak strength of the four crystal planes of each sample is very weak, as presented in the graph. This seems to be due to the fly ash contents, which results in the reinforcement's better coverage of the aluminum alloy matrix. As shown in the graph, the peaks of the unreinforced Al (111) crystal planes are significantly enhanced. The peaks of the other three crystal planes, on the other hand, remained unchanged. The formation of $\mathrm{CuAl}_{2}$ groups in self-assembled molecules on the $\mathrm{Al}$ (111) plane is responsible for this. There were no discernible peaks of $\mathrm{Ca}$ in the XRD patterns of the hybrid AMCs. This could be due to the dissolution of the calcium atoms during the fabrication phase of the AMC production.

\subsection{Density and Porosity.}

The effect of the reinforcements on the density and porosity of the cast samples was investigated. From Figure 6 (a), it can be inferred that the density of the samples decreased with the increasing weight fraction of the reinforcements. The density of the cast samples was $2.68 \mathrm{~g} / \mathrm{cm}^{3}, 2.63 \mathrm{~g} / \mathrm{cm}^{3}, 2.59 \mathrm{~g} / \mathrm{cm}^{3}, 2.52 \mathrm{~g} / \mathrm{cm}^{3}$, and $2.42 \mathrm{~g} / \mathrm{cm}^{3}$ for samples L0, L1, L2, L3, and $\mathrm{L} 4$, respectively. The reduction in the density was attributed to the presence of reinforcements that are less dense than the aluminum matrix. The results indicate that the hybrid reinforcements are ideal for achieving weight reduction of the aluminum alloy. An indication of the presence of pores in the cast AMC samples is the difference between the experimental density and the theoretical density. This result is summarized in Figure 6 (b). The percentage porosity obtained via equation 3 was used to mathematically quantify the cast hybrid AMC samples' porosity. It was shown that increasing the weight fraction of the reinforcements steadily increased the level of porosity of the aluminum matrix composite. The increased porosity of samples with increasing weight fraction of the reinforcements could be 
attributed to the formation of pores caused by the trapped air bubbles during the fabrication process. The increased porosity is also a result of the segregation of the reinforcing particles, leading to voids' formation.

(a)

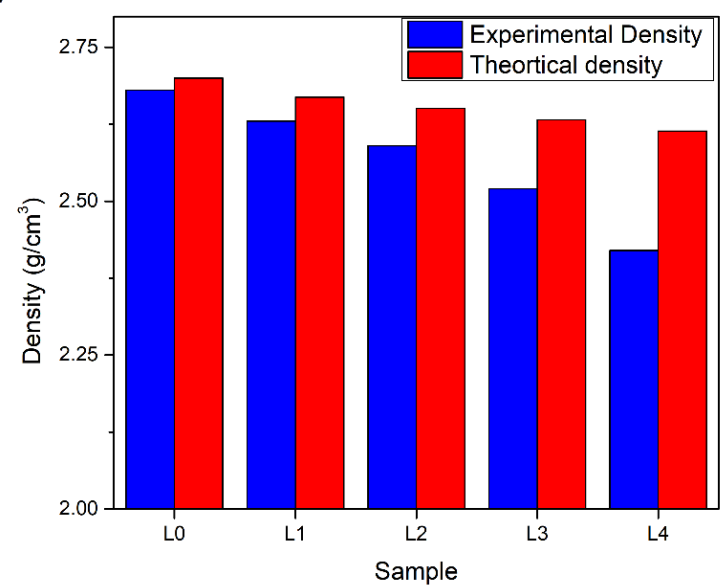

(b)

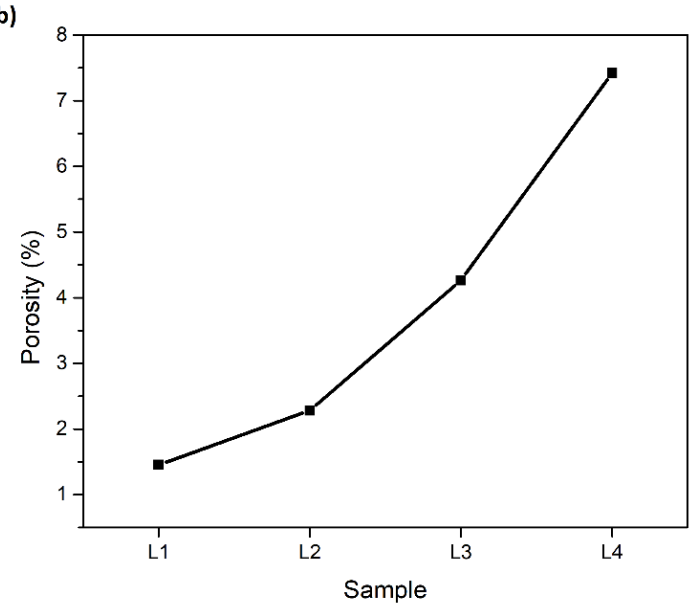

Figure 6. (a) Experimental vs. theoretical densities of the samples; (b) Porosity of the hybrid AMCs.

\subsection{Mechanical properties.}

Figure 6 shows the microhardness of the cast samples. The hardness analysis was characterized by the development of a trend that saw the microhardness of the cast AMCs increase with increasing weight fraction of the hybrid reinforcements up to sample L3 (fly ash 7.5 wt. \% and CES 2.5 wt.\%). A decline in the microhardness was reported for sample L4 (fly ash 10 wt. $\%$ and CES 2.5 wt.\%). Compared to the base metal, the microhardness of sample L1 improved by $10.71 \%$. There was a steady improvement in $24.4 \%$ and $31.08 \%$ microhardness for samples L2 and L3, respectively. The presence of the reinforcement improved the microhardness due to the increment in the dislocation densities at the reinforcement-matrix interface [34].

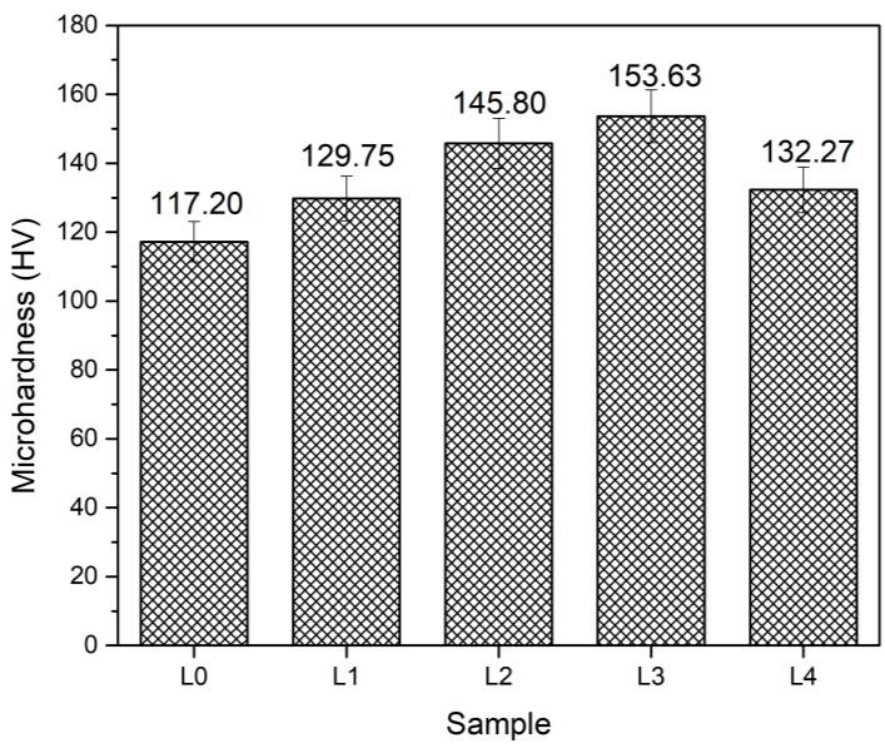

Figure 7. Variation of microhardness among the cast hybrid AMCs.

The improved hardness is also due to the presence of the hard particles responsible for the resistance of movement between individual grains during the application of the load. The improved hardness in the composites compared to the base metal is also due to the grain refinement brought about by incorporating the reinforcing phases into the aluminum matrix. 
The improved hardness for samples L1 to L3 is also due to the adequate bonding between the hybrid reinforcements and the matrix phase, which restricts the movement of dislocations in the cast hybrid AMCs. According to Shaikh et al. [35], the improvement in the microhardness is a function of the formation of dislocations due to the thermal expansion mismatch between the ductile aluminum matrix and the fly ash and CES reinforcements. The reported decline in the microhardness for sample L4 is due to the heavy presence of pores, agglomerates, and segregation of the reinforcing particles, as evident in the morphology studies depicted in Figure 3.

The behavior of the cast samples under the application of uniaxial tensile loading was studied in this investigation. The stress-strain curves for the tensile strength are shown in Figure 8 (a), while the variation of the tensile strength is depicted in Figure 8 (b). The tensile strength analysis revealed improvements in samples L1, L2, and L3 of 4.98\%, 3.03\%, and 1.14\%, respectively. The improvements in the tensile strength could be attributed to the uniform dispersion of the hybrid reinforcements in the aluminum matrix, as discussed in the examination of the microstructure. Hassan and Aigbodion [36] stated that the addition of the reinforcing particles improves the tensile strength by transferring load from the aluminum matrix to the hard reinforcements due to existing differences in elastic constants. Evident from the metallography examination of the samples, the distribution of the reinforcements along the grain boundaries of the cast hybrid AMCs is responsible for the load transfer from the ductile aluminum phase to the hard-brittle reinforcing phases. A decline in tensile strength was reported up to sample L4 (10 wt.\% fly ash and $2.5 \mathrm{wt} \% \mathrm{CES}$ ). The presence of pores created due to entrapped gases formed during the cooling of the cast, segregation, and agglomeration of the reinforcements has been attributed to being responsible for reducing the tensile strength. These formed air pockets during the solidification reduce the tensile strength of the cast AMC because the failure mechanism during the application of the uniaxial load is initiated at the formed voids.

(a)
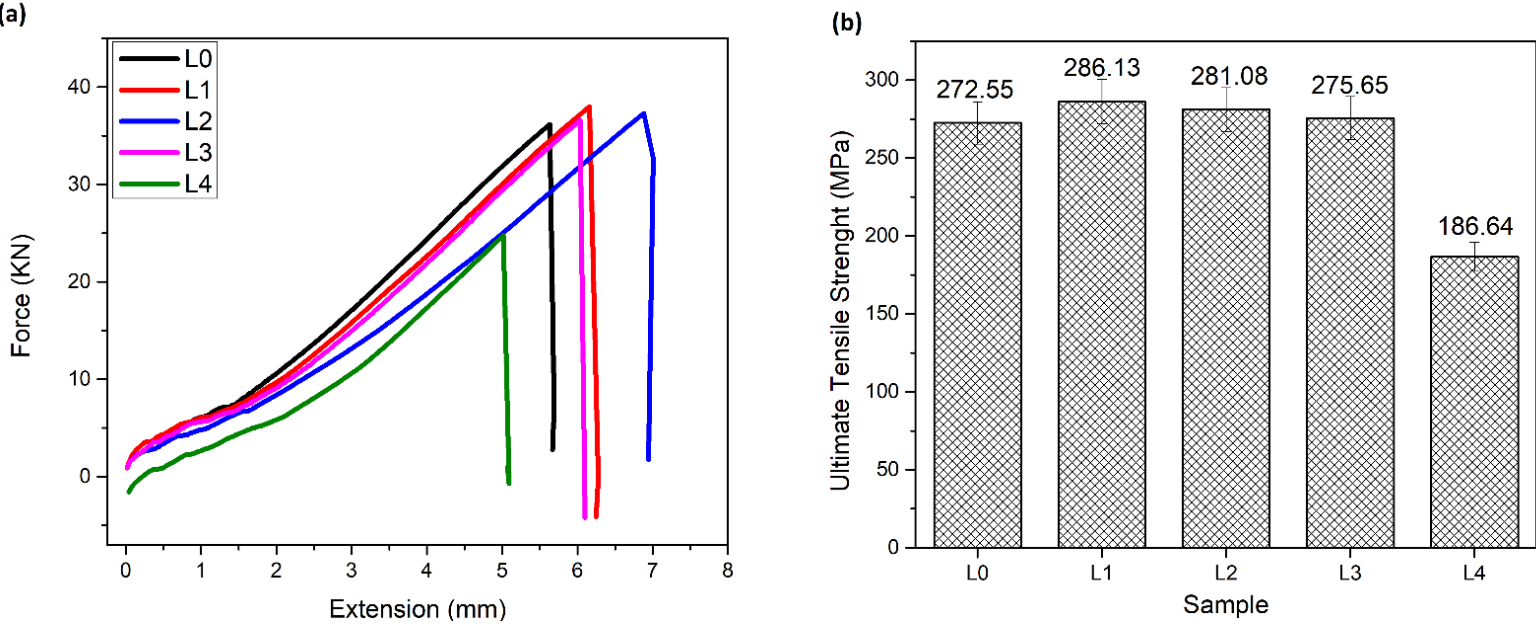

Figure 8. (a) Ultimate tensile strength (UTS); (b) Percentage elongation graph for the cast samples.

The ductility of the cast samples obtained as the percentage elongation is shown in Figure 9. The trend shows a reduction in ductility with an increasing weight fraction of the hybrid reinforcement. The dispersal of the hard-brittle reinforcements along the grain boundaries resulted in a reduction in ductility. In comparison to the base metal under consideration, the presence of the hard reinforcement hybrid particles is responsible for the reduction in ductility. Another reason for the reduction in ductility of the composites is the 
presence of the $\mathrm{CuAl}_{2}$ intermetallic phase, which was analyzed via the Xray diffractometer is responsible for the reduction in ductility [37].

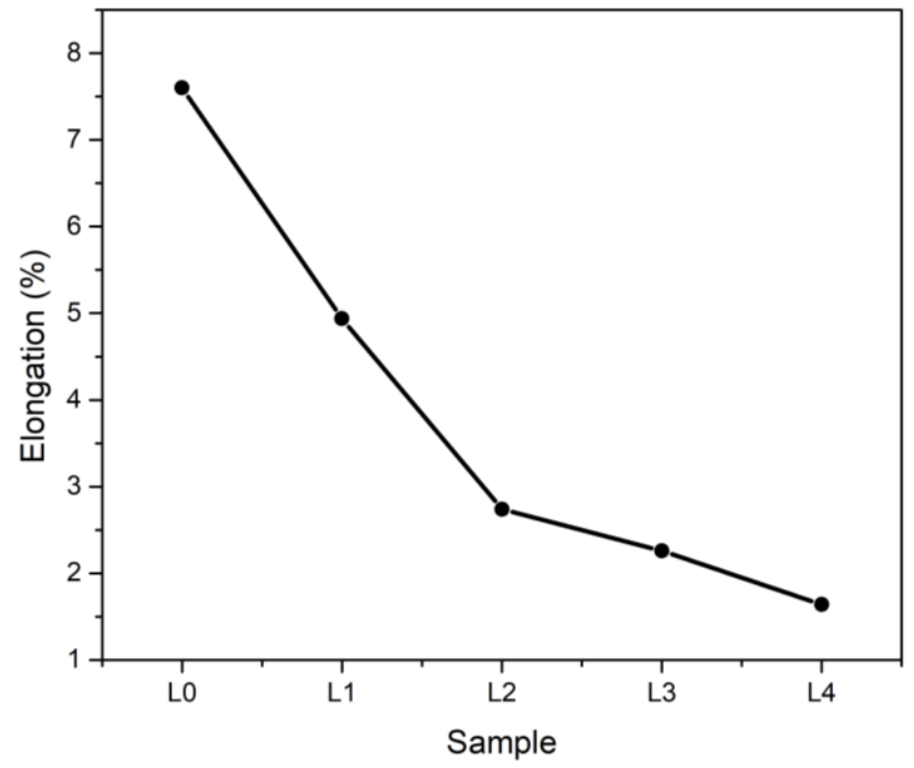

Figure 9. Ductility variation of the cast samples.

The study of the behavior of the cast samples subjected under compressive loading revealed a trend similar to the tensile loading behavior. Figure 10 shows that the compressive strength of the cast composites was improved compared to that of the base metal. The sample with the best compressive strength was sample L1. This could be attributed to adequate interfacial bonding between the reinforcements and the matrix. The relatively lower porosity compared to samples L2, L3 and L4 also played a role in the higher compressive strength. The sample showed an improvement of $17.48 \%$ compared to the base metal. The uniform dispersal of the hybrid reinforcements in the aluminum alloy is responsible for the improved compressive strength. Generally, the improvement in the compressive strength is due to the hardening of the aluminum alloy with the fly ash and carbonized eggshell particles [38]. In addition, the presence of the hybrid.

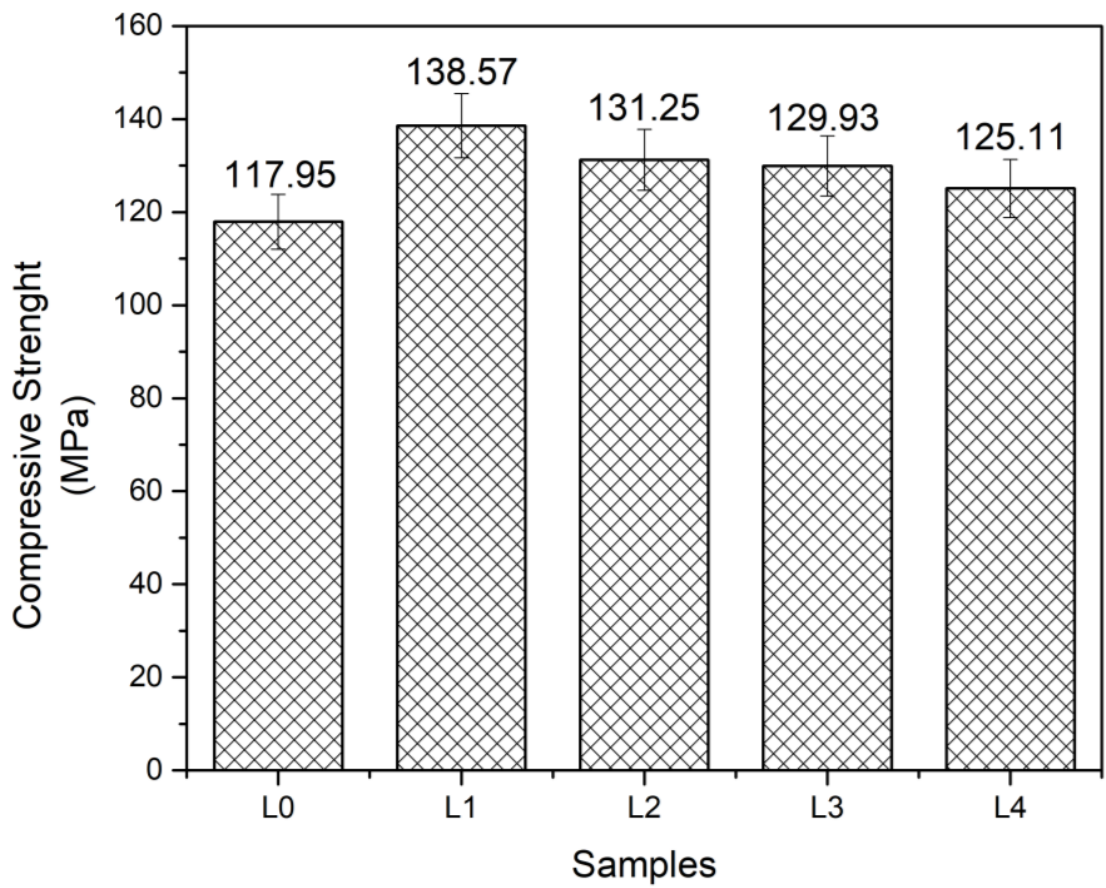

Figure 10. Compressive strengths for the cast samples. 


\subsection{Tribology.}

The wear characteristics and mechanisms for the cast samples were investigated to understand the effect of the hybrid reinforcements on the aluminum alloy matrix.

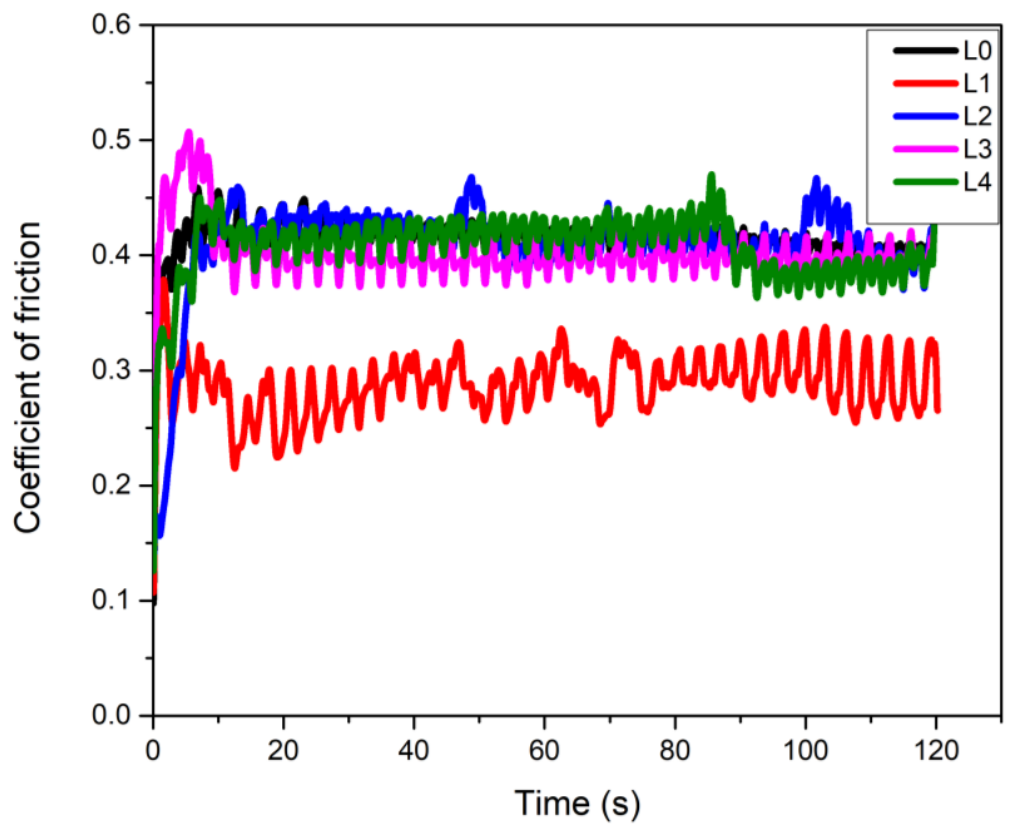

Figure 11. Coefficient of friction against time.

This was achieved using the already described parameters used to evaluate the COF and volumetric wear rate. The effect of the hybrid reinforcements on the COF under the applied load is shown in Figure 11. The average coefficient of friction at a glance was used to describe the wear resistance of the cast samples. The average COF for samples L0, L1, L2, L3, and L4 were $0.416,0.289,0.386,0.403$, and 0.409 , respectively. These results indicate that the cast AMCs possess improved wear resistance compared to the base metal. Although this was the case, it was also noticed that the COF decreased with the increasing weight fraction of the reinforcement. This trend was due to the increased formation of voids already discussed in the porosity analysis of the cast samples.

In Figure 11, the evaluation of the $\mathrm{COF}$ against time showed an initial rise which was characteristic of the initial contact of the steel ball on the surface of the samples. Another indicator for the initial rise in the COF was also a result of the thermal softening of the surface of the samples with the application of the load while the steel counterface was sliding across the surface of the cast samples. The conversion of wear mechanism from adhesive to abrasive is also an indicator of improved wear resistance overtime during the application of load. With increasing sliding time, the COF decreased and settled. This was brought about by forming a mechanically mixed layer that works by forming a protective barrier that reduced the contact between the steel ball and the surface of the samples. For the AMCs, the presence of the hybrid reinforcements improved the wear resistance, as evident by the reduced COF compared to the base metal. These hard reinforcing particles work to restrict the flow of the aluminum matrix during the sliding of the steel ball. In addition to this, the presence of the reinforcements also works to reduce the contact area between the sliding steel ball and the surface of the cast AMC. Another reason for the improved wear resistance could be the presence of wear debris, which is an indication of adhesive wear. The deposition of the wear debris reduces the direct contact of the steel counterface on the AMC, thereby temporarily improving its wear resistance. This, 
in turn, leads to the initiation of abrasive wear, which results in the micro plowing of the AMC's surface.

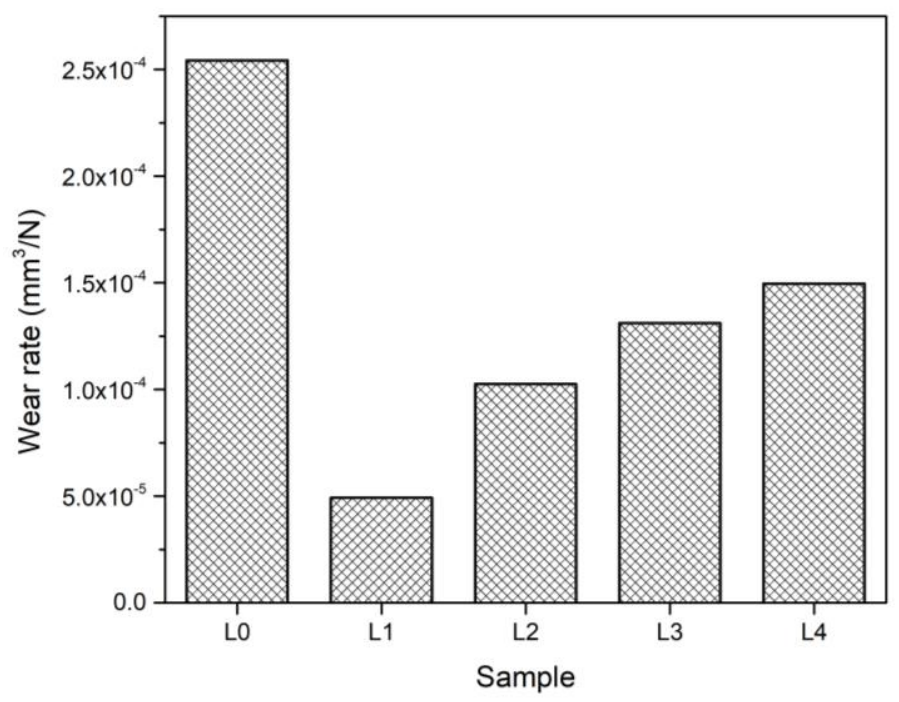

Figure 12. Wear rate for the cast samples under different loads.

The wear rate of the cast samples under consideration is shown in Figure 12. The volumetric wear rate indicates that the presence of the hybrid reinforcing particles can considerably improve the cast AMCs' wear resistance. The wear rate was lowest for sample L1, indicating that the sample possesses the best wear resistance compared to all the samples under investigation. The reduction in the volumetric wear rate was $30.46 \%, 7.14 \%, 3.03 \%$, and $1.68 \%$ for samples L1, L2, L3, and L4, respectively, which shows that the wear resistance of the hybrid AMCs was improved.

The wear mechanism of the cast samples under investigation was studied using SEM. The micrographs of samples L0 and L1 are shown in Figure 13. The major wear mechanisms in AMCs are abrasion, adhesion, fretting, and delamination [40]. For all the cast samples being studied, the SEM micrographs show that the major wear mechanisms of the samples were adhesive wear, delamination, and abrasive wear.
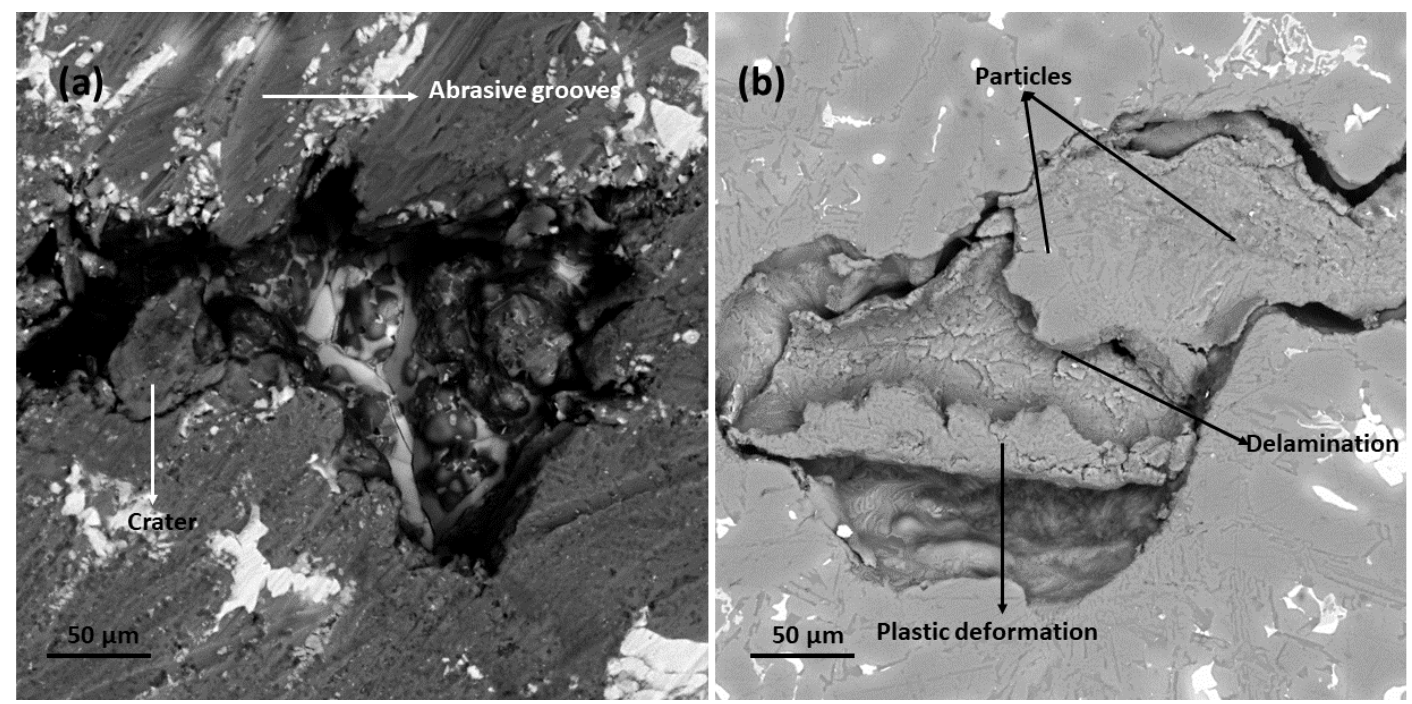

Figure 13. Wear micrographs for (a) Sample L0; (b) Sample L1.

The inspection of the worn surface of samples L2 shows a combination of plastic deformation, which indicates the presence of adhesive wear mechanisms and delamination. 
The plastic deformation could be attributed to the increased temperature due to the action of the ball on the surface of the AMC. Delamination wear mode occurred in both samples LO and L1. This could have been due to the work hardening due to the applied loads, which resulted in the formation of cracks [41]. The formation of craters is a result of erosive wear, which could be attributed to the harder reinforcement debris cutting through the metal surface at a relatively higher sliding speed. The craters could also have been formed due to the localized cyclic stresses.

\subsection{Electrochemical studies.}

The potentiodynamic study aided in the analysis of the corrosion characteristics of the cast samples under consideration. The polarization tests on the cast samples were done in a $3.5 \% \mathrm{NaCl}$ medium. As depicted in the Tafel plot shown in Figure 14 (a), the analysis exhibits both passive and active corrosion states. The shift of the potentiodynamic curves of the samples under investigation to the anodic region suggests better corrosion resistance.

(a)

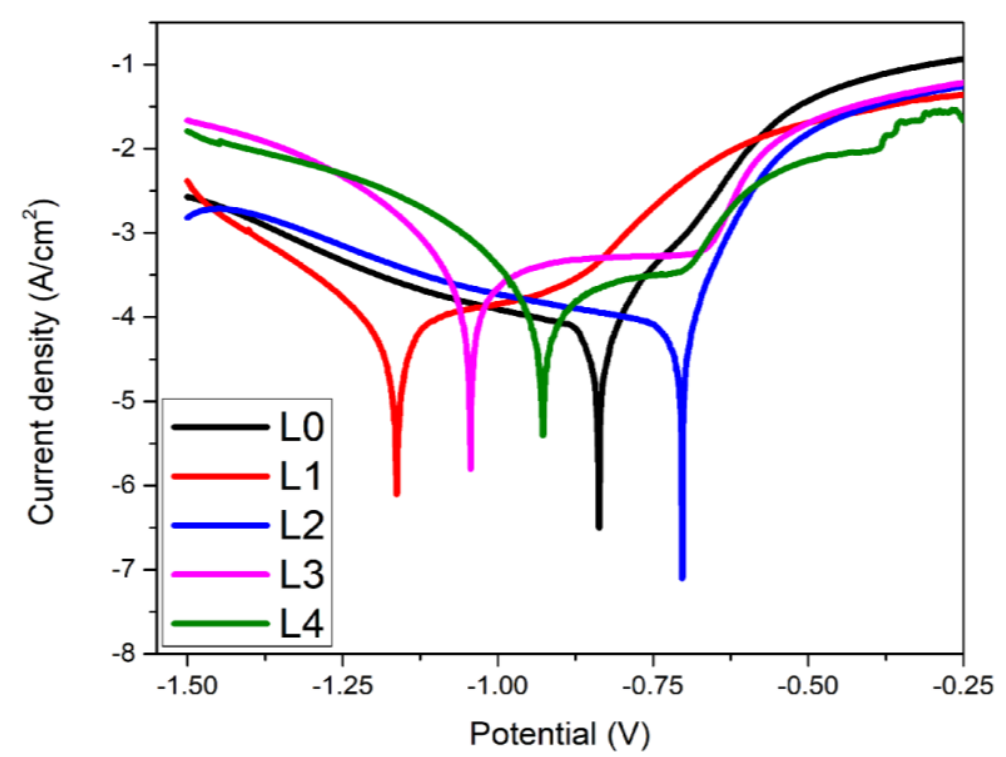

(b)

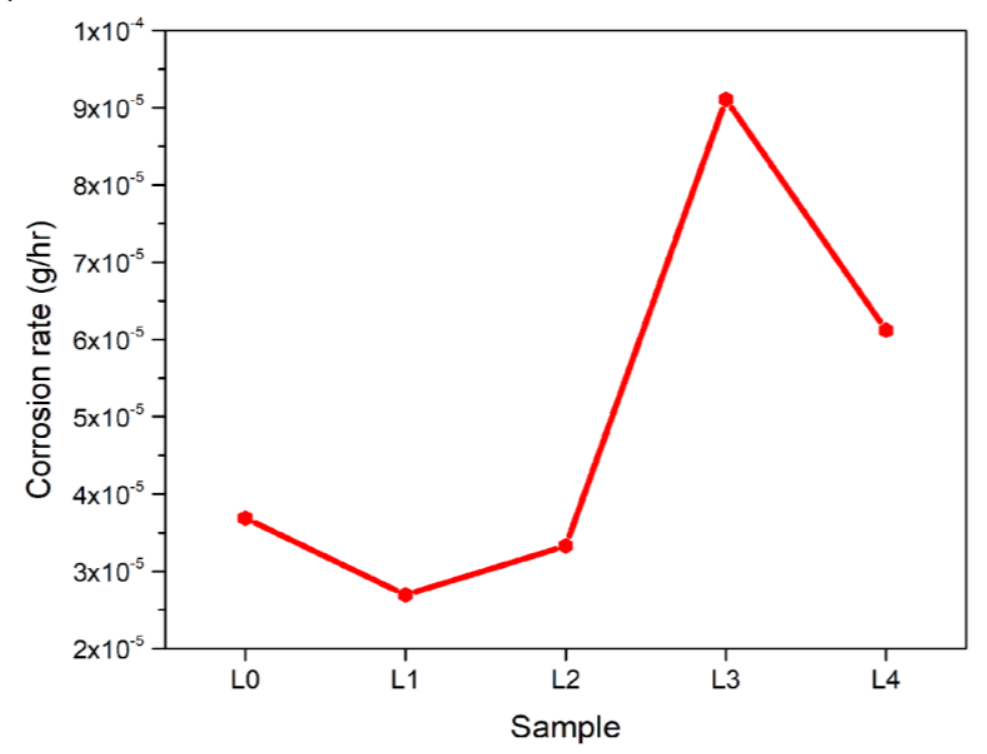

Figure 14. (a) Tafel plots for the cast samples; (b) Corrosion rate variation of the cast samples. 
Observations from the Tafel plots in Figure 14 (a) show that the presence of the chloride ions in the corrosion medium causes a dissolution of the passive layers formed on the surface of the samples. The results of the potentiodynamic polarization test summarized in table 5 indicate that the sample L1 has the lowest corrosion rate of $2.70 \times 10^{-5} \mathrm{~g} / \mathrm{hr}$. The improvement could be due to the anodic inhibition of the hybrid reinforcing particles [42]. In addition, the improvement in the corrosion resistance of the AMCs is due to the formation of a passive layer on the surface of the samples because of the reduction reaction of the oxygen atoms. With increased exposure to the chloride corrosion medium, the formed passive layer becomes relatively unstable and eventually deteriorates, forming localized pits. According to Akinwamide et al. [43], the corrosion mechanism characterized by this phenomenon is the migration/ penetration of the oxide ions, which diminishes and eventually destroys the passive oxide layers. The eventual increasing corrosion rates of the cast AMCs with increasing weight fraction of the reinforcement was due to the increasing porosity brought about by the increased viscosity and agglomeration of reinforcements. These anomalies become points for the initiation of the corrosion mechanics described earlier.

Table 5. Summary of the results for the potentiodynamic polarization analysis.

\begin{tabular}{c|c|c|c|c|c} 
Sample & $\boldsymbol{\beta}_{\mathbf{c}}$ & $\boldsymbol{\beta}_{\mathbf{a}}$ & $\begin{array}{c}\text { Corrosion potential } \\
\mathbf{( V )}\end{array}$ & $\begin{array}{c}\text { Current density } \\
\left(\mathbf{A} / \mathbf{c m}^{\mathbf{2}}\right)\end{array}$ & Corrosion rate (g/hr) \\
\hline L0 & 1.590 & 8.077 & -0.838 & $1.10 \times 10^{-4}$ & $3.69 \times 10^{-5}$ \\
\hline L1 & 6.589 & 2.245 & -1.159 & $8.04 \times 10^{-5}$ & $2.70 \times 10^{-5}$ \\
\hline L2 & 1.478 & 13.564 & -0.703 & $9.93 \times 10^{-5}$ & $3.33 \times 10^{-5}$ \\
\hline L3 & 7.666 & 2.855 & -1.042 & $2.71 \times 10^{-4}$ & $9.11 \times 10^{-5}$ \\
\hline L4 & 7.261 & 3.215 & -0.926 & $1.82 \times 10^{-4}$ & $6.12 \times 10^{-5}$
\end{tabular}

Figure 15 shows the corroded surface of samples L0 and L1. The degradation of the surfaces of sample L1 is attributed to the preferential dissolution of the more anodic aluminum alloy matrix in place of the cathodic fly ash/CES reinforcements particles. Corrosion of AMCs is usually initiated at areas of physical or chemical heterogeneity such as reinforcement/matrix interface, defect, intermetallic, mechanically damaged region, grain boundary, inclusion, or dislocation [44]. The analysis of the corroded surface of the samples shows that the main form of corrosion in the $3.5 \% \mathrm{NaCl}$ medium is localized pitting. This finding has been reported in [39] and [40] in analyzing corrosion mechanisms of different AMCs. The micrographs of sample L1 show that the corrosion mechanism involves the dissolution of the surface of the aluminum alloy and the formation of relatively small localized pits.
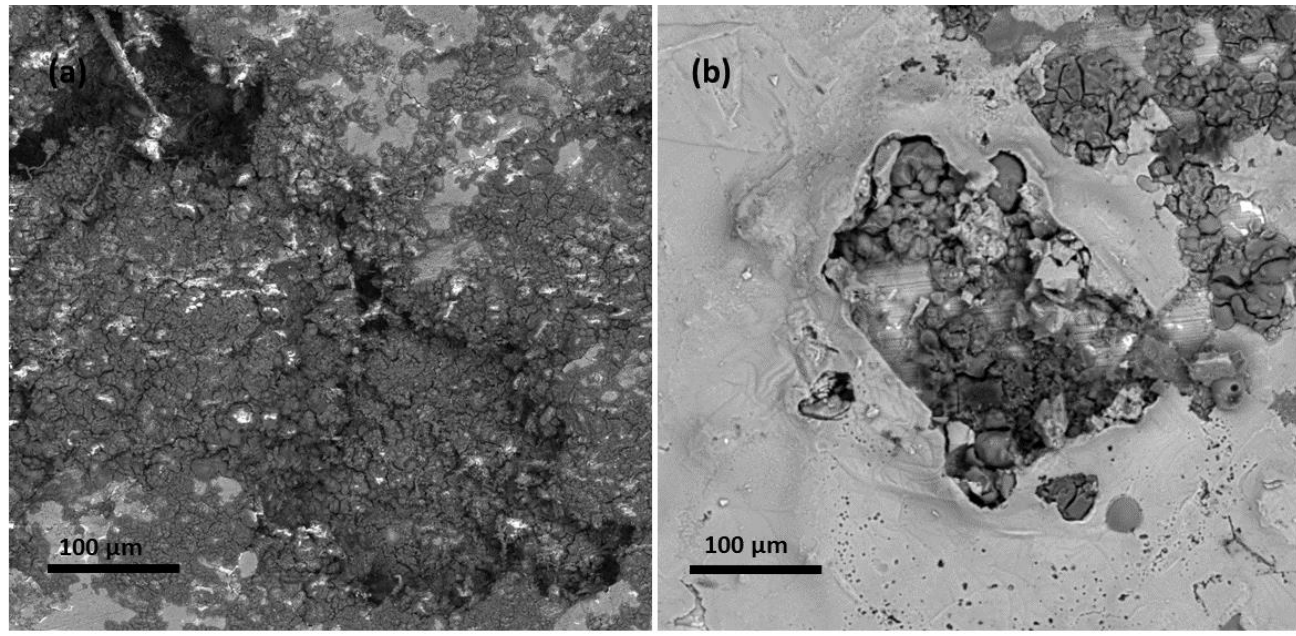

Figure 15. Micrographs of the corroded surface for samples (a) L0; (b) L1. 


\section{Conclusions}

This work was done to investigate the effect of fly ash and carbonized eggshells on the density, mechanical properties, wear, and corrosion resistance of Al-Si12. From the investigations, the following conclusion has been drawn.

The microstructure studies of the cast AMCs showed that the dispersion of the hybrid reinforcements in the aluminum matrix was fairly uniform. The increase in weight fraction of the reinforcements resulted in the increased formation of agglomerates and eventual segregation of the particles. Increasing the weight fraction of the reinforcements results showed that the density of the cast AMCs is inversely proportional to the porosity.

Increasing the weight fraction of the reinforcements improved the microhardness up to the $7.5 \mathrm{wt} . \%$ fly ash sample, while the tensile strength decreased with increasing weight fractions of the reinforcements. It was established that the decrease was due to the increasing agglomeration and porosity of the cast hybrid AMC samples with increasing weight fraction of the reinforcements. The compressive strength was maximum by $17.48 \%$ for $2.5 \mathrm{wt} \%$ fly ash sample.

Although the wear resistance increased with the increasing weight fraction of the reinforcement, the wear resistance of all the cast AMCs was improved compared to the base metal. The analysis of the wear mechanism showed the presence of predominantly abrasion, adhesion, and delamination.

Corrosion resistance for the cast AMCs was lowest for the $2.5 \mathrm{wt} . \%$ and $5.0 \mathrm{wt} . \%$ fly ash samples. Indicating improvements in the corrosion resistance compared to the base metal. The main corrosion mechanism based on the analysis of the corroded samples was localized pitting.

\section{Funding}

This research received no external funding.

\section{Acknowledgments}

This research has no acknowledgment.

\section{Conflicts of Interest}

The authors declare no conflict of interest.

\section{References}

1. Balasubramanian, M. Composite Materials and Processing 2014, 1st ed. Boca Raton : CRC Press.

2. Lino Alves, F.J.; A.M. Baptista, and A.T. Marques. Metal and ceramic matrix composites in aerospace engineering 2016. Elsevier Ltd.

3. Nathan, V.B.; Soundararajan, R.; Abraham, C.B.; Rahman, F.A. Evaluation of Mechanical and Metallurgical Properties on Aluminium Hybrid Metal Matrix Composites. Materials Today: Proceedings 2019, 18, 25202529, https://10.1016/j.matpr.2019.07.109.

4. Bodunrin, M.O.; Alaneme, K.K.; Chown, L.H. Aluminium matrix hybrid composites: A review of reinforcement philosophies; Mechanical, corrosion and tribological characteristics. Journal of Materials Research and Technology 2015, 4, 434-445, https://10.1016/j.jmrt.2015.05.003.

5. Haghshenas, M. Metal-Matrix Composites. Reference Module in Materials Science and Materials Engineering 2016, 1-28, Elsevier. 
6. Aigbodion, V.S.; Ezema, I.C. Multifunctional A356 alloy / PKSAnp composites: Microstructure and mechanical properties. Defence Technology 2020, 16, 731-736, https://10.1016/j.dt.2019.05.017.

7. Ramanathan, A.; Krishnan, P.K.; Muraliraja, R.A. review on the production of metal matrix composites through stir casting - Furnace design, properties, challenges, and research opportunities. Journal of Manufacturing Processes 2019, 42, 213-245, https://10.1016/j.jmapro.2019.04.017.

8. Ononiwu, N.H.; Akinlabi, E.T.; Ozoegwu, C.G.; Aigbodion, V.S.A Concise Review of the effects of hybrid particulate reinforced aluminium metal matrix composites on the microstructure, density and mechanical properties in Lecture Notes in Mechanical Engineering: Advances in Manufacturing Engineering, S. E. Seyed, A. Mokhotar, and F. Yusof, Eds. Springer Singapore 2020, 433-443, https://doi.org/10.1007/978-98115-5753-8_40.

9. Kumaraswamy, H.S.; Bharat, V.; Krishna Rao, T. Influence of Mechanical \& tribological Behaviour of Al 2024 MMC Fabricated by Stir Casting Technique-A Review. Materials Today: Proceedings 2018, 5, 1196211970, https://10.1016/j.matpr.2018.02.170.

10. Rajesh, S.; Devaraj, D.; Sudhakara Pandian, R.; Rajakarunakaran, S. Multi-response optimization of machining parameters on red mud-based aluminum metal matrix composites in turning process. International Journal of Advanced Manufacturing Technology 2013, 67, 811-821, https://10.1007/s00170-012-4525-1.

11. Ononiwu, N.H.; Akinlabi, E.T. Effects of ball milling on particle size distribution and microstructure of eggshells for applications in metal matrix composites. Materials Today: Proceedings 2020, 2, 1049-1053, https://10.1016/j.matpr.2020.02.209.

12. Dwivedi, S.P.; Srivastava, A.K.; Maurya, N.K.; Maurya, M. Microstructure and mechanical properties of Al 6061/ $\mathrm{Al}_{2} \mathrm{O}_{3} /$ Fly-Ash composite fabricated through stir casting. Annales de Chimie: Science des Materiaux 2019, 43, 341-348, https://10.18280/acsm.430510.

13. Sunil Kumar Reddy, K.; Kannan, M.; Karthikeyan, R.; Sripad, A.; Jain, P.K. Investigation of thermal and mechanical properties of Al7020/SiC/graphite hybrid metal matrix composites. Materials Today: Proceedings 2020, 26, 2746-2753, https://10.1016/j.matpr.2020.02.574.

14. Kumarasamy, S.P.; Vijayananth, K.; Thankachan, T.; Pudhupalayam Muthukutti, G. Investigations on mechanical and machinability behavior of aluminum/flyash cenosphere/Gr hybrid composites processed through compocasting. Journal of Applied Research and Technology 2017, 15, 430-441, https://10.1016/j.jart.2017.05.005.

15. Siddesh Kumar, N.G.; Suresh, R.; Shiva Shankar, G.S. High temperature wear behavior of A12219/n$\mathrm{B}_{4} \mathrm{C} / \mathrm{MoS}_{2}$ hybrid metal matrix composites. Composites Communications 2019, 19, 61-73, https://10.1016/j.coco.2020.02.011.

16. Dey, A.; Pandey, K.M. Characterization of fly ash and its reinforcement effect on metal matrix composites: A review. Reviews on Advanced Materials Science 2016, 44, 168-181.

17. David Raja Selvam, J.; Dinaharan, I.S. Vibin Philip, and P.M. Mashinini. Microstructure and mechanical characterization of in situ synthesized $\mathrm{AA} 6061 /\left(\mathrm{TiB}_{2}+\mathrm{Al}_{2} \mathrm{O}_{3}\right)$ hybrid aluminum matrix composites. Journal of Alloys and Compounds 2018, 740, 529-535, https://10.1016/j.jallcom.2018.01.016.

18. Alaneme, K.K.; Eze, H.I.; Bodunrin, M.O. Corrosion behaviour of groundnut shell ash and silicon carbide hybrid reinforced Al-Mg-Si alloy matrix composites in 3.5\% $\mathrm{NaCl}$ and $0.3 \mathrm{M} \mathrm{H}_{2} \mathrm{SO}_{4}$ solutions. Leonardo Electronic Journal of Practices and Technologies 2015, 14, 141-158.

19. Vinod, B.; Ramanathan, S.; Anandajothi, M. A novel approach for utilization of agro-industrial waste materials as reinforcement with $\mathrm{Al}-7 \mathrm{Si}-0.3 \mathrm{Mg}$ matrix hybrid composite on tribological behaviour. $S N$ Applied Sciences 2019, 1, 1-15, https://10.1007/s42452-018-0066-z.

20. Ononiwu, N.H.; Ozoegwu, C.G.; Madushele, N.; Akinlabi, E.T. Characterization, machinability studies and multi-response optimization of AA 6082 hybrid metal matrix composite. The International Journal of Advanced Manufacturing Technology 2021, 116, 1-19, https://doi.org/10.1007/s00170-021-07549-7.

21. Dwivedi, S.P.; Sharma, S.; Mishra, R.K. Microstructure and mechanical behavior of A356/SiC/Fly-ash hybrid composites produced by electromagnetic stir casting. Journal of the Brazilian Society of Mechanical Sciences and Engineering 2014, 37, 57-67, https://10.1007/s40430-014-0138-y.

22. Mahanta, S.; Chandrasekaran, M.; Samanta, S.; Arunachalam, R. Multi-response ANN modelling and analysis on sliding wear behavior of Al7075/B 4 C/fly ash hybrid nanocomposites. Materials Research Express 2019, 6, 1-19, https://10.1088/2053-1591/ab28d8.

23. Shaikh, M.B.N.; Arif, S.; Siddiqui, M.A. Fabrication and characterization of aluminium hybrid composites reinforced with fly ash and silicon carbide through powder metallurgy. Materials Research Express 2018, 5, 1-13, https://10.1088/2053-1591/aab829. 
24. Bose, S.; Pandey, A.; Mondal, A. Comparative analysis on aluminium-silicon carbide hybrid green metal matrix composite materials using waste eggshells and snail shell ash as reinforcements. Materials Today: Proceedings 2018, 5, 27757-27766, https://10.1016/j.matpr.2018.10.011.

25. Dwiwedi, S.K.; Srivastava, A.K.; Chopkar, M.K. Wear Study of Chicken Eggshell-Reinforced Al6061 Matrix Composites. Transactions of the Indian Institute of Metals 2019, 72, 73-84, https://10.1007/s12666-0181463-0.

26. Dwivedi, S.P.; Sharma, S. A comparative study of waste eggshells, green metal matrix composites. Journal of Composite Materials 2017, 51, 2407-2421, https://10.1177/0021998316672295.

27. Sharma, S.; Dwivedi, S.P. Effects of waste eggshells and $\mathrm{SiC}$ addition on specific strength and thermal expansion of hybrid green metal matrix composite. Journal of Hazardous Materials 2017, 333, 1-9, https://10.1016/j.jhazmat.2017.01.002.

28. Idusuyi, N.; Oviroh, P.O.; Adekoya, A.H. A study on the corrosion and mechanical properties of an Al6063 reinforced with eggshell ash and rice husk ash. ASME International Mechanical Engineering Congress and Exposition, Proceedings (IMECE) 2018, 12, 1-8, https://10.1115/IMECE2018-86662.

29. Durowoju, M.O.; Asafa, T.B.; Sadiku, E.R.; Diouf, S.; Shongwe, M.B. Improving mechanical and thermal properties of graphite - aluminium composite using $\mathrm{Si}, \mathrm{SiC}$ and eggshell particles. Journal of Composite Materials 2020, 54, 2365-2376, https://10.1177/0021998319892058.

30. Asuke, F. Effects of bone particles on the properties and microstructure of polypropylene/bone ash particulate composites. Results in Physics 2012, 2, 135-141, https://10.1016/j.rinp.2012.09.001.

31. Ononiwu, N.H.; Ozoegwu, C.G.; Jeremiah, O.; Akinlabi, E. T. Effect of particle size on the microstructure and distribution of fly ash for metal matrix composite applications. Materials Today: Proceedings 2021, 26, 1049-1053, https://10.1016/j.matpr.2020.11.227.

32. Manikandan, R.; Arjunan, T.V.; Akhil, A.R. Studies on microstructural characteristics, mechanical and tribological behaviours of boron carbide and cow dung ash reinforced aluminium (Al 7075) hybrid metal matrix composite. Composites Part B: Engineering 2020, 183, 1-18, https://10.1016/j.compositesb.2019.107668.

33. Sharma, S.; Dwivedi, S.P. Effects of waste eggshells and SiC addition on specific strength and thermal expansion of hybrid green metal matrix composite. Journal of Hazardous Materials 2017, 333, 1-9, https://10.1016/j.jhazmat.2017.01.002.

34. Saravanan, S.D.; Senthilkumar, M.; Shankar, S. Effect of particle size on tribological behavior of rice husk ash-reinforced aluminum alloy (AlSi10mg) matrix composites. Tribology Transactions 2013, 56, 1156-1167, https://10.1080/10402004.2013.831962.

35. Shaikh, M.B.N.; Arif, S.; Aziz, T.; Waseem, A.; Shaikh, M.A.N.; Ali, M. Microstructural, mechanical and tribological behaviour of powder metallurgy processed $\mathrm{SiC}$ and RHA reinforced Al-based composites. Surfaces and Interfaces 2019, 15, 166-179, https://10.1016/j.surfin.2019.03.002.

36. Hassan, S.B.; Aigbodion, V.S. Effects of eggshell on the microstructures and properties of $\mathrm{Al}-\mathrm{Cu}-$ Mg/eggshell particulate composites. Journal of King Saud University - Engineering Sciences 2013, 27, 4956, https://10.1016/j.jksues.2013.03.001.

37. Sahoo, R.R.; Patra, A.; Karak, S.K. Fabrication of nano $\mathrm{ZrO}_{2}$ dispersed novel W 79 Ni 10 Ti 5 Nb 5 alloy by mechanical alloying and pressureless sintering. IOP Conference Series: Materials Science and Engineering 2017, 178, 1-11, https://10.1088/1757-899X/178/1/012015.

38. Manimaran, R.; Jayakumar, I.; Mohammad Giyahudeen, R.; Narayanan, L. Mechanical properties of fly ash composites-A review. Energy Sources, Part A: Recovery, Utilization and Environmental Effects 2018, 40, 887-893, https://10.1080/15567036.2018.1463319.

39. Fernandes, P. Effect of fly ash and ball milling time on CNT-FA reinforced aluminium matrix hybrid composites. Materials Research Express 2019, 6, 1-9, https://10.1088/2053-1591/ab1e20.

40. Idusuyi, N.; Olayinka, J.I. Dry sliding wear characteristics of aluminium metal matrix composites: A brief overview. Journal of Materials Research and Technology 2019, 8, 3338-3346, https://10.1016/j.jmrt.2019.04.017.

41. Halil, K.; Ismail, O.I.; Sibel, D.; Ramazan, Çi. Wear and mechanical properties of Al6061/SiC/B $\mathrm{B}_{4} \mathrm{C}$ hybrid composites produced with powder metallurgy. Journal of Materials Research and Technology 2019, 8, 53485361, https://10.1016/j.jmrt.2019.09.002.

42. Akinwamide, S.O.; Akinribide, O.J.; Olubambi, P.A. Influence of Ferrotitanium and Silicon Carbide Addition on Structural Modification, Nano hardness and Corrosion Behaviour of Stir-Cast Aluminium Matrix Composites. Silicon 2020, 13, 1-12, https://doi.org/10.1007/s12633-020-00733-6. 
43. Akinwamide, S.O.; Abe, B.T.; Akinribide, O.J.; Obadele, B.A.; Olubambi, P.A. Characterization of microstructure, mechanical properties and corrosion response of aluminium-based composites fabricated via casting - a review. The International Journal of Advanced Manufacturing Technology 2020, 109, 975-991, https://doi.org/10.1007/s00170-020-05703-1.

44. Kanayo, K.; Apata, P. Corrosion and wear behaviour of rice husk ash - Alumina reinforced Al-Mg-Si alloy matrix hybrid composites. Journal of Materials Research and Technology 2013, 2, 188-194, https://10.1016/j.jmrt.2013.02.005.

45. Ikumapayi, O.M.; Akinlabi, E.T.; Abegunde, O.O.; Fayomi, O.S.I. Electrochemical investigation of calcined agrowastes powders on friction stir processing of aluminium-based matrix composites. Materials Today: Proceedings 2020, 26, 3238-3245, https://10.1016/j.matpr.2020.02.906.

46. Rodríguez Pérez, O. Corrosion Behavior of A356/SiC Alloy Matrix Composites in 3.5\% NaCl Solution. International Journal of Electrochemical Science 2019, 14, 7423-7436, https://10.20964/2019.08.33. 